\title{
Flora vascular da Mata da Pavuna, Botucatu, SP, Brasil
}

\author{
Vascular flora of "Mata da Pavuna", Botucatu, SP, Brazil
}

Leonardo Biral ${ }^{1,3} \&$ Julio Antonio Lombardi ${ }^{2}$

\begin{abstract}
Resumo
A Mata da Pavuna é um fragmento de Floresta Estacional Semidecidual em um cânion com afloramento rochoso e solo raso, localizado no município de Botucatu, Estado de São Paulo. Foram amostradas as espécies vasculares em estádio reprodutivo e identificadas até o menor nível taxonômico possível. Foram encontradas 386 espécies em 84 famílias. Fabaceae foi a família com maior número de espécies (44), seguida de Asteraceae (34), Euphorbiaceae (18), Poaceae (17), Malvaceae (14), Bignoniaceae e Solanaceae (12). Entre as Pteridophyta sensu lato, as famílias mais diversas foram Pteridaceae (nove espécies) e Polypodiaceae (sete). Comparado a outros levantamentos florísticos extensos na Mata Atlântica, os resultados ressaltam a elevada diversidade florística local, bem como a presença de espécies típicas de formações xerofíticas sugerindo a ocorrência de um encrave de vegetação seca nesta região. Destacamos também o primeiro registro de Pellaea ovata (Desv.) Weath. (Pteridaceae) para o Brasil.
\end{abstract}

Palavras-chave: afloramento rochoso, floresta estacional semidecidual, floresta seca, Mata Atlântica, plantas vasculares.

\begin{abstract}
"Mata da Pavuna" is a fragment of Seasonal Semideciduous Forest located in a canyon characterized by rocky outcrops and shallow soil, in Botucatu municipality, São Paulo state. We collected fertile vascular plants and identified them to the lowest possible taxonomic level. We found 386 species in 84 families; Fabaceae was the most diverse family with 44 species, followed by Asteraceae (34), Euphorbiaceae (18), Poaceae (17), Malvaceae (14), Bignoniaceae (12) and Solanaceae (12). In the Pteridophyta sensu lato the most diverse families were Pteridaceae (nine species) and Polypodiaceae (seven). Compared to other comprehensive floristic surveys carried out in the Atlantic Forest these results show high floristic diversity with typical species from xerophytic vegetation, suggesting the presence of an enclave of dry forest. Pellaea ovata (Desv.) Weath. (Pteridaceae) is first reported here for Brazil.
\end{abstract}

Key words: rock outcrops, semideciduous seasonal forest, dry forest, Atlantic Forest, vascular plants.

\section{Introdução}

Estudos florísticos devem estar entre as principais fontes de informação para planos que incluam preservação, conservação ou manejo de áreas com vegetação nativa (Gómez-Pompa \& Nevling Jr. 1988). Apesar disso, levantamentos extensivos que compreendam todos os hábitos são raros. Os numerosos estudos fitossociológicos realizados no estado de São Paulo incluem apenas espécies arbóreas ou arbóreo-arbustivas, em detrimento daqueles que contemplem os demais hábitos ocorrentes em comunidades florestais (Martins 1989). Espécies com outros hábitos de vida, notavelmente lianas e epífitas, são importantes no componente florístico e estrutural das florestas tropicais (Gentry \& Dodson 1987; Schnitzer \& Bongers 2002).

Dos biomas brasileiros a Mata Atlântica é considerado o de maior complexidade florística e estrutural, considerando-se sua área em relação ao bioma Amazônico (Sobral \& Stehmann 2009). Ao se estender em faixa praticamente

Este artigo possui material adicional em sua versão eletrônica.

${ }^{1}$ UNESP - Universidade Estadual Paulista, Instituto de Biociências de Rio Claro, Pós-Graduação em Ciências Biológicas, Av. 24-A 1515, 13506-900, Rio Claro, SP, Brasil.

${ }^{2}$ UNESP - Universidade Estadual Paulista, Instituto de Biociências de Rio Claro, Depto. Botânica, Av. 24-A 1515, 13506-900, Rio Claro, SP, Brasil.

${ }^{3}$ Autor para correspondência: e-mail: biral@rc.unesp.br 
contínua, desde o Nordeste até o Rio Grande do Sul, ao longo de 27 graus de latitude sul e com grandes variações de altitude, abarca diversas formações vegetacionais, desde florestais até campestres (IBGE 1991; Pinto \& Brito 2005). Esse bioma ocupava cerca de $12 \%$ do território nacional e sua flora é estimada por Myers et al. (2000) em 20 mil espécies de plantas vasculares, das quais cerca de oito mil seriam endêmicas. Em levantamento mais recente, Stehmann et al. (2009) encontraram um número menor de espécies para o Domínio Atlântico (14.552), porém maior taxa de endemismo - 48\% (6.933 espécies).

Hoje, em razão do processo histórico de ocupação, a Mata Atlântica, que chegou a ocupar entre 1 e 1,5 milhão de $\mathrm{km}^{2}$, está reduzida a apenas 7 a $8 \%$ de sua área inicial (GalindoLeal \& Câmara 2005). Apesar dessa estimativa situar essa formação como um dos hotspots de biodiversidade mundiais, i.e. áreas que perderam ao menos $70 \%$ de sua cobertura vegetal original e contém pelo menos 1500 espécies de plantas vasculares endêmicas (Myers et al. 2000; Mittermeier et al. 2004), podemos considerála apenas razoavelmente conhecida. Exemplo disso é o fato que de 1990 a 2006 mais de 1.100 espécies provenientes deste bioma foram descritas como novas, perfazendo mais de $40 \%$ do total de descrições de taxa brasileiros nesse período (Sobral \& Stehmann 2009).

No ritmo lento em que os estudos florísticos estão sendo efetuados nos trópicos, a maioria da biodiversidade vegetal natural será perdida antes mesmo de ser inventariada (Wheeler 2004). Isso é evidenciado pelas taxas de destruição das áreas de vegetação nativa em todas as fisionomias, assim como o grande número de espécies da flora brasileira consideradas raras (Rapini et al. 2009) ou ameaçadas de extinção (Brasil 2008). Evidencia-se, portanto, a necessidade urgente de se conhecer, de maneira abrangente, a composição florística do que atualmente resta da vegetação, mesmo alterada.

No Estado de São Paulo, a maioria dos remanescentes da Mata Atlântica está na forma de fragmentos pouco protegidos, comumente isolados e inseridos em paisagens antropizadas, e sob forte pressão do ambiente externo. Os maiores e mais bem preservados fragmentos são de Floresta Ombrófila Densa localizados na Serra do Mar, local em que a topografia acidentada dificulta a prática de atividades humanas (agricultura, transporte, moradia, etc.) que possam colocar em risco a vegetação (Aguiar et al. 2003). A Floresta Estacional Semidecidual (FES), por sua vez, se apresenta bastante fragmentada em função de perturbações de variada ordem (Leitão-Filho 1987). Atualmente verifica-se que boa parte da biodiversidade restante é encontrada em manchas de vegetação, pouco estudadas e negligenciadas por medidas protecionistas (Viana \& Pinheiro 1998).

Ainda pouco conhecida, a Floresta Estacional Decidual (FED) no Estado de São Paulo está relacionada a condições edáficas e não climáticas, em consequência de solos rasos e pouco profundos, onde o acúmulo de água é deficiente, levando a deciduidade foliar acentuada (Ivanauskas \& Rodrigues 2000). Esse tipo de vegetação é caracterizado justamente pela presença de espécies deciduais, com mais de $50 \%$ dos indivíduos do dossel despidos de folhagem no período desfavorável (IBGE 1991). Em razão das variações no solo, as florestas deciduais apresentam distribuição naturalmente fragmentada e podem coexistir muito próximas das semideciduais (Kotchetkoff-Henriques et al. 2005).

A Mata da Pavuna é um fragmento florestal que, pelo seu tamanho, conservação e localização, é de grande importância local e regional. O objetivo desse estudo é descrever e caracterizar sua composição florística, bem como verificar a presença de espécies invasoras, raras ou ameaçadas, e compará-la com outras listagens a fim de discutir características vegetacionais. Assim, avaliamos se no Estado de São Paulo, sendo um dos mais estudados do ponto de vista botânico, trabalhos de florística ainda podem nos trazer novas informações nesta área.

\section{Material e Métodos}

Área de estudo

A Mata da Pavuna está localizada no município de Botucatu, SP $\left(22^{\circ} 83^{\prime} 80^{\prime \prime} \mathrm{S}\right.$ e 48 51'14"W, alt. 630-761 m) e possui ao todo 378,49 ha (Fig. 1). Esse fragmento, que abarca várias propriedades, é coberto principalmente por FES (IBGE 1991; Kronka et al. 2005). Está presente no entorno da calha dos rios Araquá e Cintra (o que dá uma forma poligonal ao 
fragmento) e inserido na bacia hidrográfica do rio Araquá, afluente do rio Tietê, e na APA Corumbataí-Botucatu-Tejupá. Conforme Decreto Estadual $\mathrm{n}^{\circ}$ 20.960, de 8 de junho de 1983 (São Paulo 1983) sua inclusão na APA se deu graças a "... preservação de elementos significativos da flora e da fauna, ao conjunto paisagístico formado, pelos rios e fontes hidrotermais contidas na cuesta".

As coletas foram efetuadas na fazenda Nossa Senhora da Saúde, propriedade outrora explorada com fins à mineração (extração de brita) e hoje tendo como principal atividade o cultivo de café e o ecoturismo. O entorno da Pavuna é marcado pelo cultivo de cana-de-açúcar e pecuária e a preservação de vegetação nativa na região é decorrência da topografia acidentada, pouco favorável às atividades humanas.

O clima na região é do tipo Tropical de Altitude (Cwa) pelo sistema de Köppen (1948) com chuvas no verão e seca no inverno. A média anual da temperatura é $20,7^{\circ} \mathrm{C}$, com mínima de $12,4^{\circ} \mathrm{C}$ em setembro e máxima de $28,1^{\circ} \mathrm{C}$ em janeiro (CEPAGRI 2010). A média anual de precipitação é de $1738,5 \mathrm{~mm}$, com mínima 27,92 $\mathrm{mm}$ em agosto e máxima de 270,15 $\mathrm{mm}$ em janeiro (dados obtidos junto à Estação Meteorológica da FCA-UNESP, Botucatu, na Fazenda Experimental de São Manuel, referentes aos anos de 2003 a 2008).

Essa região está assentada sobre a formação geológica da Cuesta Basáltica, com suas nascentes na região do Reverso da Cuesta e a foz na Depressão Periférica. Os solos do Reverso são provenientes dos arenitos do grupo Bauru, formações Marília e Adamantina, e do Front dos basaltos do grupo São Bento, Serra Geral (Almeida $\&$ Melo 1981). O solo em diversos pontos é raso e pedregoso, com a presença de afloramentos rochosos e declive acentuado (varia de 30 a $90^{\circ}$, predominante entre 40 e $50^{\circ}$ ).

Tratamento dos dados

As coletas de material botânico foram realizadas mensalmente entre abril de 2009 e agosto de 2010, na região sul do fragmento. A restrição das coletas a uma fração da área foi em decorrência do tamanho total do local e acessibilidade. Foi visitada a área compreendida entre os rios Araquá e Cintra, que inclui da vegetação do topo de morros e afloramentos rochosos, até a vegetação

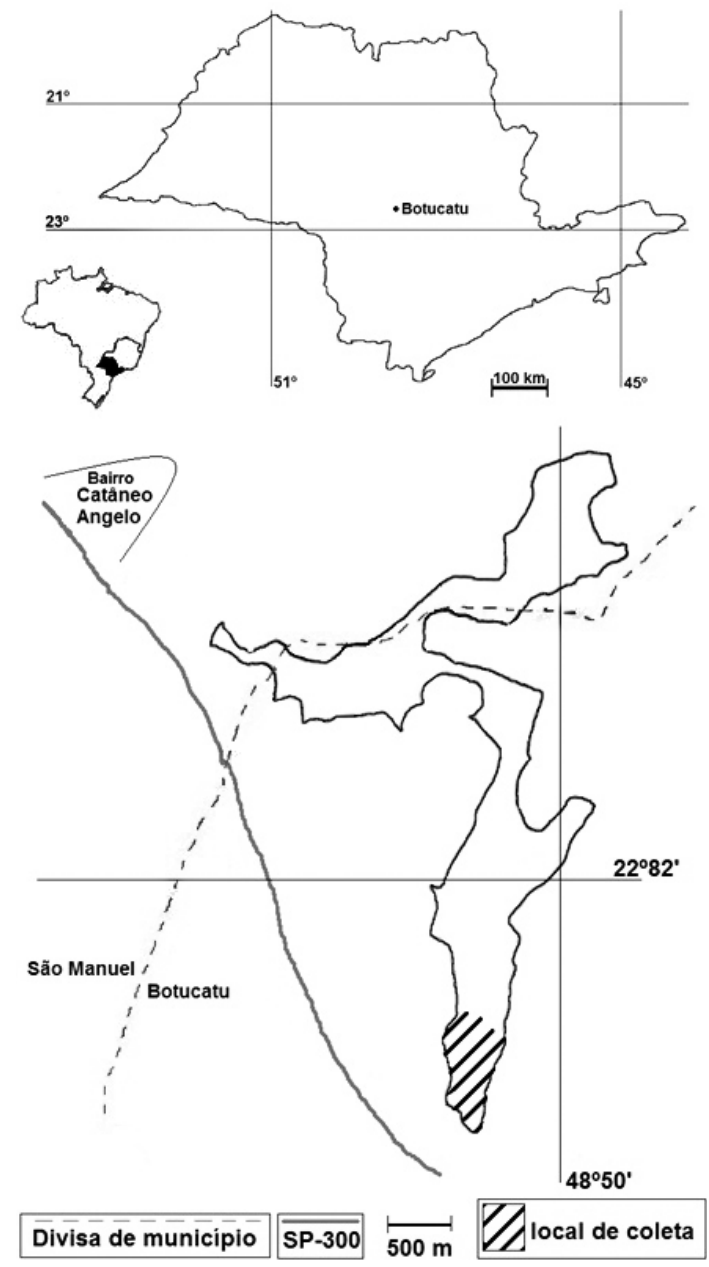

Figura 1 - Localização de Botucatu, no estado de São Paulo, e o fragmento florestal da Mata da Pavuna no detalhe.

Figure 1 - Location of Botucatu municipality on the São Paulo State and, in detail, the delimitation of Mata da Pavuna.

ciliar perene. A borda do fragmento, quando de possível acesso, foi percorrida, bem como as áreas de vegetação secundária contíguas.

Foram coletados indivíduos de plantas vasculares em estado fértil, incluindo-se ruderais e exóticas cultivadas. Foram consideradas ruderais aquelas espécies exóticas encontradas em áreas alteradas e perturbadas (Woitke \& Dietz 2002), fortemente alteradas pela atividade humana, como pastos, áreas cultivadas e/ou locais descampados adjacentes ao fragmento. As exóticas foram todas aquelas espécies não-nativas, segundo a Lista de Espécies da Flora do Brasil (2011). As espécies estritamente cultivadas, mesmo nativas, estão 
inclusas no Apêndice (ver a versão eletrônica deste artigo), mas foram excluídas de todos os demais resultados por entendermos que elas não estão naturalizadas e as suas ocorrências são decorrentes de manejo, não fazendo parte da comunidade vegetal original.

Todo material coletado foi herborizado conforme os procedimentos habituais da coleta botânica e incorporado ao Herbarium Rioclarense (HRCB) na coleção "Florística vascular da Mata da Pavuna". A identificação das espécies se deu por emprego de bibliografia especializada, comparação com material depositado nos herbários HRCB e SP e consulta a especialistas. Para as angiospermas, adotou-se o sistema de classificação proposto em APG II (2003) e para Pteridophyta sensu stricto seguiu-se Smith et al. (2006). O hábito de cada espécie foi verificado em campo usando-se como critério as definições de Gonçalves \& Lorenzi (2007), sendo considerados arbustos escandentes os indivíduos arbustivos cujos troncos e ramos cresciam arqueados e nitidamente apoiando-se sobre outras espécies. As espécies consideradas ameaçadas foram aquelas indicadas no Livro Vermelho das Espécies Vegetais Ameaçadas do Estado de São Paulo (Mamede et al. 2007). A nomenclatura botânica seguiu a indicação do Missouri Botanical Garden (2010), a abreviação dos nomes dos autores conforme Brummit \& Powell (1992) e os herbários citados de acordo com Thiers (2010).

\section{Resultados e Discussão}

Foram encontradas 386 espécies, pertencentes a 280 gêneros e 84 famílias (ver Apêndice na versão eletrônica deste artigo). As famílias fanerogâmicas com maior número de espécies foram: Fabaceae (41 espécies), Asteraceae (34), Euphorbiaceae (18), Poaceae (17), Malvaceae (14), Bignoniaceae (12), Solanaceae (12) e Commelinaceae (nove). Diversas outras famílias (Bromeliaceae, Cactaceae, Cyperaceae, Orchidaceae e Sapindaceae) estiveram presentes com oito espécies cada. Em Fabaceae, as subfamílias Faboideae, Caesalpinoideae, Mimosoideae e Cercideae apresentaram, respectivamente, 23,10 , sete e uma espécie cada. As dez famílias mais ricas perfizeram total de 172 espécies, ou 44,8\% do total amostrado. Entre as Pteridophyta s.l. foram coletadas 28 espécies, pertencentes a nove famílias e 20 gêneros, correspondendo a $7,2 \%$ do total dos táxons coletados. Pteridaceae e Polypodiaceae foram as famílias mais representativas com nove e sete espécies respectivamente. Do total, apenas 32 táxons $(8,3 \%)$ não foram identificados até espécie.

Mesmo se restringindo a uma porção do fragmento, o presente estudo registrou elevado número de espécies. Em comparação com outras áreas de FES onde amplos levantamentos de flora foram efetuados (Tab. 1), a Mata da Pavuna apresentou maior riqueza que os levantamentos na Mata de Santa Genebra (Guaratini et al. 2008) e na Estação Ecológica Paulo de Faria (Stranghetti \& Ranga 1998). Os levantamentos de Cardoso et al. (2009) em FES na Bahia e Ivanauskas \& Rodrigues (2000) em São Paulo (em vegetação classificada pelos autores como FED) apresentaram riqueza menor. Além da evidência dessas áreas possuírem de fato, menor riqueza, o baixo número de espécies apresentado pode estar relacionado também com o período menor de coleta e a área mais restrita do levantamento efetuado nesses dois trabalhos.

O levantamento realizado no Alto Paranapanema apresentou maior número de espécies (Cielo-Filho et al. 2009). Contribuiu para essa elevada riqueza o fato do levantamento ser realizado em área de grande extensão de vegetação contínua e enquadrada em duas unidades de conservação (floresta estadual e estação ecológica), o que proporciona um maior resguardo para a vegetação. A inclusão de considerável parcela (114 espécies) de material vegetativo ao levantamento também eleva o número de espécies, pois material estritamente vegetativo não costuma ser incluso em levantamentos florísticos, sendo mais frequente apenas em estudos fitossociológicos.

Fabaceae está presente entre as três famílias mais ricas em todos os levantamentos comparados, cinco deles em primeiro lugar (Tab. 1). Fabaceae, por ser uma família grande e com espécies distribuídas por diversos hábitos, desde herbáceas e lianas até arbóreas (Queiroz 2009), tende a ser a principal família em levantamentos extensivos, em especial na FES (Leitão-Filho 1987). Malvaceae, que teve sua circunscrição ampliada pela proposta contida em APG II (2003), tende a partir de agora a ser bem representada nos levantamentos florísticos em florestas estacionais semideciduais (Guarantini et al. 2008). Bignoniaceae, Sapindaceae e Apocynaceae 


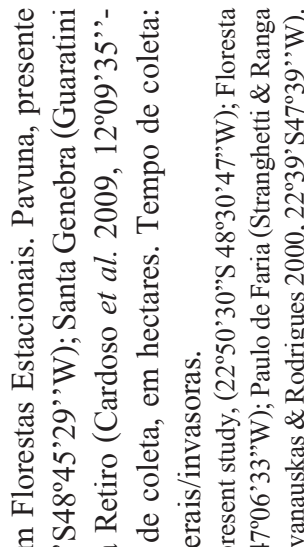

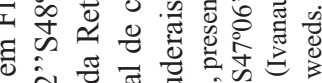
\% ते

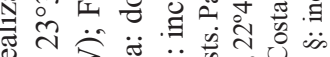

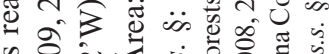

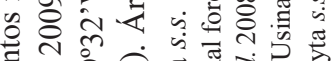

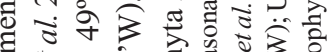
चี जै ळ

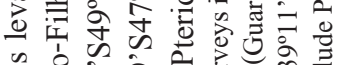
के 응 के

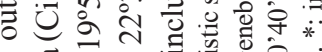

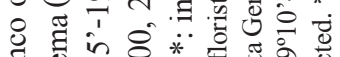

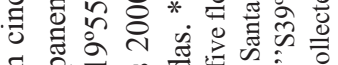

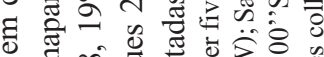
0

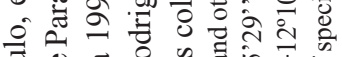
है क्ष

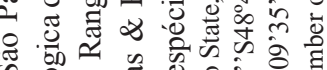
㐘 है

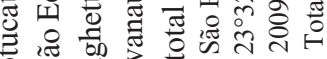

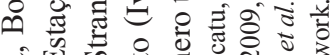

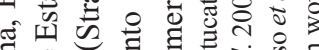

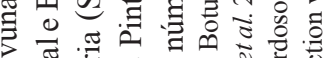

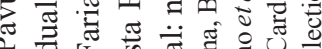

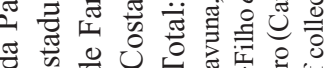

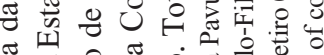

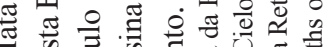

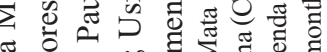

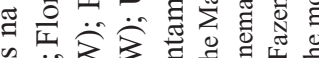

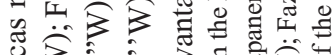

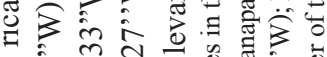

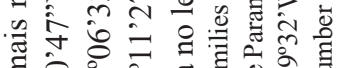

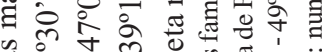

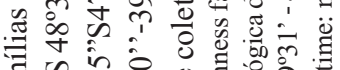
言 స్ के के ฝे

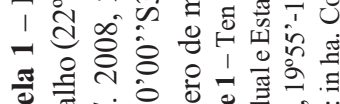

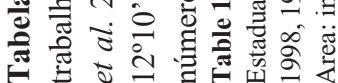

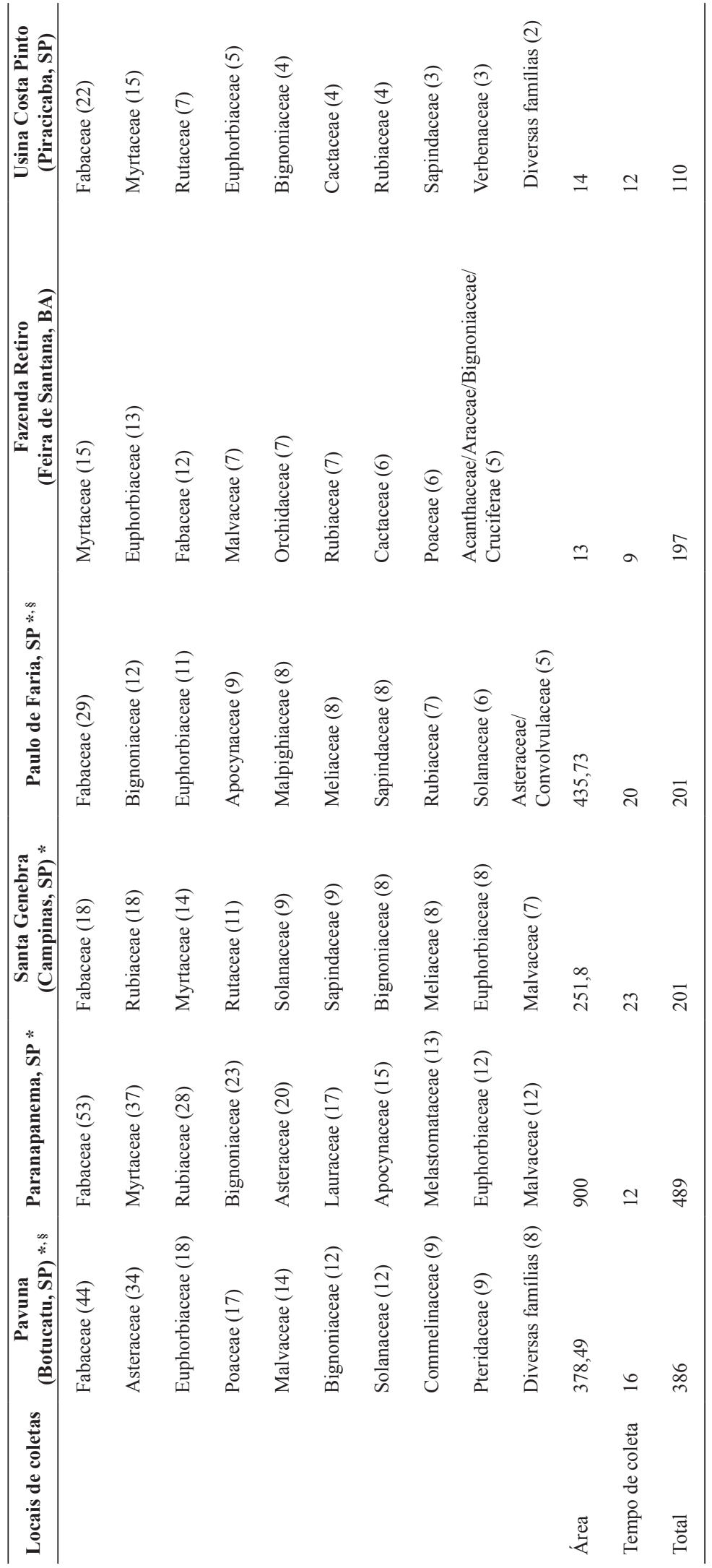


são as famílias com espécies trepadeiras mais destacadas, sendo comumente citadas entre as 10 famílias mais importantes (Santos et al. 2009). Neste caso específico aqui apresentado, Commelinaceae foi bem amostrada devido à presença de espécies herbáceas no sub-bosque das matas ciliares. Também chamou a atenção a riqueza de Bromeliaceae e Cactaceae, fato incomum para levantamentos em FES. Pouco ricas na Pavuna foram Lauraceae e Melastomataceae, assim como verificado em FED por Ivanauskas \& Rodrigues (2000).

A pouca representatividade de Myrtaceae e Rubiaceae em comparação aos outros levantamentos (Tab. 1), visto essas famílias estarem entre as predominantes em áreas de Mata Atlântica (Oliveira-Filho \& Fontes 2000), pode estar associada ao sub-bosque pouco sombreado e à sazonalidade climática. Tanto a deciduidade foliar como a declividade acentuada do relevo favorecem a incidência luminosa até os estratos inferiores da comunidade, o que contribui para a riqueza de espécies herbáceas. Isso pode ser averiguado pela riqueza de espécies de Asteraceae, Poaceae, Commelinaceae e Euphorbiaceae, esta última muito bem representada por herbáceas, em detrimento das arbóreas. O estrato arbóreo é dominado por espécies de Fabaceae, Meliaceae e Rutaceae nas áreas de solo mais profundo. A presença de representantes dessas famílias é recorrente na FES (Leitão-Filho 1987).

Analisando a quantidade de espécies em comum compartilhada pela Pavuna com outros cinco estudos florísticos, a maior semelhança $(32,7 \%)$ se deu com o levantamento de dois pequenos fragmentos de FED na Usina Pinto Costa, Piracicaba (Ivanauskas \& Rodrigues 2000) (Tab. 2). A proporção de espécies partilhadas com essa área é maior que em outros levantamentos em FES. A menor similaridade quanto às espécies em comum se deu na FES da Bahia (Cardoso et al. 2009): esse baixo número pode estar relacionado ao tamanho da área de amostragem, alterações antrópicas ou divergências florísticas, devido sobretudo a distância geográfica. Os estudos florísticos na FES no estado de São Paulo (Stranghetti \& Ranga 1998; Guaratini et al. 2008; Cielo-Filho et al. 2009) indicaram um compartilhamento de espécies em torno de 17,9 e $27,9 \%$. A maior similaridade com um levantamento em FED, e não FES, ressalta uma característica decidual da vegetação na Pavuna.
Aspecto marcante da Mata da Pavuna é o solo pouco profundo com a presença de afloramentos rochosos em vários pontos de sua cobertura. Afloramentos rochosos apresentam microclima distinto marcado por insolação e temperatura do ar mais elevadas que na vegetação circundante (Porembski 2007). O reflexo dessas condições abióticas particulares é detectado na composição florística peculiar desses afloramentos que, na Mata da Pavuna, são dominados por espécies tipicamente xerofíticas (Aechmea distichantha, Praecereus euchlorus e Cereus hildmannianus) raramente encontradas na vegetação circundante. Nesses afloramentos encontramos espécies lenhosas citadas para a FED do Estado de São Paulo (Ivanauskas \& Rodrigues 2000; Kotchetkoff-Henriques et al. 2005) como por exemplo, Cereus hildmannianus, Croton gracilipes, Guettarda uruguensis, Macherium scleroxylon, Peltophorum dubium e outras espécies mais generalistas.

$\mathrm{O}$ estrato arbóreo da FED é visivelmente diferenciado dos locais de FES, de solo profundo. Essas vegetações podem ser diferenciadas pelo dossel: descontínuo e baixo $(5 \mathrm{~m})$ na FED e contínuo e alto (ca. 10-15 m) na FES. A espécie arbórea dominante na FED é Aspidosperma riedelii, com indivíduos menos numerosos de Cereus hildmannianus e Strychnos brasiliensis. A presença de $A$. riedelii está associada a solos pedregosos (Marcondes-Ferreira 2004), não sendo verificada na FES na Pavuna. Além do solo mais raso e pedregoso, a deciduidade foliar pronunciada na FED ajuda a diferenciá-la das áreas de FES.

Prado \& Gibbs (1993) analisaram as formações florestais secas na América do Sul e determinaram três áreas nucleares: as caatingas no Nordeste brasileiro, o vale do rio Uruguai, Missões, Argentina e Paraguai e o núcleo Piedmont (sudoeste boliviano e noroeste argentino), todas com espécies em comum, porém ausentes em outras formações vegetacionais, como o cerrado. Das espécies comuns às áreas florestais secas indicadas por Prado \& Gibbs (1993), Carica quercifolia, Patagonula americana, Peltophorum dubium e Aspidosperma riedelii ocorrem na Mata da Pavuna.

Com a presença de solo raso e pedregoso e uma parcela das espécies ocorrentes típicas das florestas secas em alguns pontos concluímos que a Mata da Pavuna detém um encrave de vegetação 
Tabela 2 - Número de espécies compartilhadas entre a Mata da Pavuna, Botucatu, São Paulo, e outros levantamentos em Florestas Estacionais. Fazenda Retiro, Paranapanema, Paulo de Faria, Santa Genebra e Usina Costa Pinto supracitados na tabela 2. Formação vegetacional: FED, Floresta Estacional Decidual; FES, Floresta Estacional Semidecidual. Área: do local de coleta, em hectares. Tempo de coleta: número de meses de coleta no levantamento.

*: inclui Pteridophyta s.s. §: inclui ruderais/invasoras.

Table 2 - Number of shared species between Mata da Pavuna, Botucatu, São Paulo State, and others surveys in seasonal forests. Fazenda Retiro, Paranapanema, Paulo de Faria, Santa Genebra and Usina Costa Pinto cited in table 2. Vegetation: FED, deciduous seasonal forest; FES, semideciduous seasonal forest; Area: in ha. Collection time: number of months of collection work. *: include Pteridophyta s.s. §: include weeds.

\begin{tabular}{lccccc}
\hline Locais de coleta & $\begin{array}{c}\text { Fazenda Retiro } \\
\text { (Feira de } \\
\text { Santana, BA) }\end{array}$ & $\begin{array}{c}\text { Paranapanema, } \\
\text { SP * }\end{array}$ & $\begin{array}{c}\text { Paulo de } \\
\text { Faria, SP } * \S \S\end{array}$ & $\begin{array}{c}\text { Santa Genebra } \\
\text { (Campinas, SP) * }\end{array}$ & $\begin{array}{c}\text { Usina Costa Pinto } \\
\text { (Piracicaba, SP) * }\end{array}$ \\
\hline $\begin{array}{l}\text { Formação } \\
\text { vegetacional }\end{array}$ & FES & FES & FES & FES & FED \\
$\begin{array}{l}\text { Tempo de coleta } \\
\text { Área }\end{array}$ & 9 & 12 & 20 & 23 & 12 \\
$\begin{array}{l}\text { Total de espécies } \\
\text { Espécies em } \\
\text { comum com a } \\
\text { Mata da Pavuna }\end{array}$ & 13 & 900 & 435,73 & 251,8 & 110 \\
\hline
\end{tabular}

decidual em meio a FES. A presença desse encrave poderia ser decorrente de um processo de retração das florestas secas dominantes na América do Sul em algum momento no Pleistoceno. Supõe-se que essas florestas secas provavelmente formaram um continuum de vegetação, mas com mudanças climáticas foram se retraindo, se encontrando atualmente na forma de encraves de vegetação xerofítica em meio à floresta tropical (Ab'Saber 1992; Prado \& Gibbs 1993).

Conforme a lista de espécies vegetais ameaçadas do Estado de São Paulo (Mamede et al. 2007), as espécies que sofrem algum grau de ameaça são apresentadas na Tabela 3 , ressaltandose a presença de duas espécies presumivelmente extintas. Uma delas, Sinningia piresiana, herbácea encontrada em afloramentos rochosos, é endêmica do Estado de São Paulo e representada, até o momento, por apenas três registros em herbário provenientes de locais de vegetação nativa os outros dois são oriundos de Descalvado e Pedregulho, depositados respectivamente em SP e ESA (A. Chautemms, com. pess.).

A coleta de Pellaea ovata representa o primeiro registro para o Brasil (Biral \& Prado 2012). Trata-se de uma herbácea subescandente com distribuição nas Américas, desde o sudoeste dos Estados Unidos (Texas) até a Argentina, presente em áreas abertas, afloramentos rochosos ou crescendo sob árvores (Tryon 1957), mas sem registros, até então, para o Brasil. Tem sido citada como ocorrente em vegetações xerofíticas (Wiggins 1946) o que parece ser o caso dessa coleta, visto que foi coletada em afloramento rochoso, sob alta incidência luminosa e permeado de espécies típicas de vegetação seca como bromélias e cactos. A coleta dessa espécie no Brasil é inusitada por estar longe da sua área de distribuição conhecida, tendo seu registro mais próximo em Salta, Argentina, uma das regiões nucleares de vegetação decidual para América do Sul (Prado \& Gibbs 1993).

Herbáceas introduzidas, potencialmente invasoras, e.g. gramíneas africanas (Hyparrhenia rufa, Melinis minutiflora, M. repens, Megathyrsus maximus), Macrothelypteris torresiana, Thelypteris dentata e Hedychium coronarium, foram coletadas em locais de vegetação alterada. Além dessas, na vegetação foram encontradas outras espécies sabidamente introduzidas no Brasil: Brugmansia suaveolens, Tecoma stans, Schefflera arboricola e Citrus limonia - provavelmente cultivadas, que 
Tabela 3 - Lista das espécies coletadas na Mata da Pavuna, Botucatu, São Paulo, ameaçadas de extinção conforme o Livro vermelho das espécies vegetais ameaçadas do Estado de São Paulo (Mamede et al. 2007). Categorias: EN (Em Perigo), EX (Presumivelmente extinta), VU (Vulnerável), NT (Quase ameaçada) Table 3 - Threatened species present in Mata da Pavuna, Botucatu, SP, São Paulo State, listed in the Livro vermelho das espécies vegetais ameaçadas do Estado de São Paulo (Mamede et al. 2007). Categories: EN (Endangered), EX (Probably Extinct), VU (Vunerable), NT (Near Threatened).

\begin{tabular}{llc}
\hline \multicolumn{1}{c}{ Família } & \multicolumn{1}{c}{ Espécie } & Categoria \\
\hline Apocynaceae & Aspidosperma riedelii & EN \\
Cactaceae & Lepismium warmingianum & NT \\
Convolvulaceae & Ipomoea bonariensis & NT \\
Gesneriaceae & Sinningia piresiana & EX \\
Malvaceae & Gaya dominguensis & VU \\
Piperaceae & Peperomia nitida & EX \\
Vitaceae & Cissus serroniana & VU \\
\hline
\end{tabular}

carregadas por dispersores a partir de sua área de plantio original naturalizaram-se na vegetação e podem ser consideradas como potencialmente invasoras. A presença dessas espécies na condição de introduzidas na vegetação é recorrente.

Os resultados destacam que a Mata da Pavuna possui rica composição de espécies vegetais vasculares, superior a de outros fragmentos florestais no interior do estado de São Paulo. A riqueza de espécies no local certamente está relacionada à diferentes ambientes e às condições abióticas. A ocorrência de um novo registro para o Brasil, bem como a nova coleta de espécies consideradas presumivelmente extintas em São Paulo mostram que o estado, mesmo sendo relativamente bem conhecido do ponto de vista florístico, ainda apresenta novidades e, portanto, levantamentos de flora ainda são necessários. Trabalhos de florística incrementam o conhecimento da vegetação e fornecem subsídios fundamentais para a taxonomia e a filogeografia. Mesmo assim tais trabalhos são pouco reconhecidos pela maioria dos periódicos científicos de maior impacto na área de botânica. A seleção de uma boa área de coleta e empenho no esforço amostral e de identificação são fundamentais para colher bons resultados na florística e contribuir para o conhecimento da distribuição e conservação da flora.

\section{Agradecimentos}

Os autores gostariam de agradecer aos especialistas que na ajudaram nas identificações, que estão devidamente citados no Apêndice (na versão eletrônica deste artigo), ao $\mathrm{CNPq}$ a concessão do auxílio financeiro e aos dois revisores anônimos as sugestões. O primeiro autor agradece a: Zelão, funcionário da propriedade Nossa Senhora da Saúde pela permissão de acesso a área; Carlos Linder, as sugestões iniciais; Ramon Bicudo e Dinival Martins, da Faculdade de Ciências Agronômicas, Unesp, Botucatu, os dados fornecidos; Fernando Luiz Sousa Ferreira, Odair José Garcia Almeida e Jefferson Prado o auxílio em campo, Hildebrando Luiz da Silva, funcionário do herbário BOTU.

\section{Referências}

Ab'Saber, A.N. 1992. A Serra do Japi, sua origem geomorfológica e a teoria dos refúgios. In: Morellato, L.P.C (ed.). História natural da Serra do Japi. Editora da UNICAMP, FAPESP, Campinas. Pp. 12-23.

Aguiar, A.P.; Chiarello, A.G.; Mendes, S.L. \& Matos, E.N. 2003. The Central and Serra do Mar corridors in the Brazilian Atlantic Forest. In: Galindo-Leão, C. \& Câmara, I.G. (eds.). The Atlantic Forest of South America: Biodiversity status, threats and outlook. Center for Applied Biodiversity Science at Conservation Internacional. Island Press, Washington D.C. Pp. 118-132.

Almeida, F.F.M. \& Melo, M.S. 1981. A Bacia do Paraná e o vulcanismo mesozóico. In: Bistrichi, C.A.; Carneiro, C.D.R.; Dantas, A.S.L. \& Ponçano, L. (eds.). Mapa Geológico do Estado de São Paulo, escala 1:500.000, vol. 1. Divisão de Minas e Geologia aplicada, Instituto de Pesquisas Tecnológicas do Estado de São Paulo S.A. - IPT, São Paulo. Pp. 46-81.

APG II. 2003. An update of the Angiosperm Phylogeny Group classification for the orders and families of flowering plants: APG II. Botanical Journal of Linnean Society 141: 399-436.

Biral, L. \& Prado, J. 2012. First record of Pellaea ovata (Pteridaceae) from Brazil. American Fern of Journal 102(1). No prelo.

BRASIL. 2008. Instrução Normativa ${ }^{\circ}$ 6. Diário Oficial da União, 24/09/2008, Seção 1, Pp. 75-83.

Brummit, R.K. \& Powell, C.E. 1992. Authors of plant names. 1ed. Royal Botanic Gardens, Kew. 732p.

Cardoso, D.B.O.S.; França, F.; Novais, J.S.; Ferreira, M.H.S.; Santos, R.M.; Carneiro, V.M.S. \& Gonçalves, J.M. 2009. Composição florística e 
análise fitogeográfica de uma floresta semidecídua na Bahia, Brasil. Rodriguésia 60: 1055-1076.

Cielo-Filho, R.; Baitello, J.B.; Pastore, J.A.; Aguiar, O.T.; Souza, S.C.P.M.; Toniato, M.T.Z.; Lima, C.R. \& Ribeiro, A.P. 2009. Ampliando a densidade de coletas botânicas na região da bacia hidrográfica do Alto Paranapanema: Caracterização florística da Floresta Estadual e da Estação Ecológica de Paranapanema. Biota Neotropica 9: 255-276.

CEPAGRI. 2010. Clima dos municípios paulistas. Disponível em $<$ http://www.cpa.unicamp.br/outrasinformacoes/clima_muni_086.html >. Acesso em 1 Dez 2010.

Galindo-Leal, C.G. \& Câmara, I.D. 2005. Status do hotspot Mata Atlântica: uma síntese. In: GalindoLeal, C.G. \& Câmara, I.D. (eds.). Mata Atlântica: Biodiversidade, Ameaças e Perspectivas. Fundação SOS Mata Atlântica, Conservação Internacional, Belo Horizonte. Pp. 3-11.

Gentry, A.H. \& Dodson, C. 1987. Contribution of nontrees to species richness of a tropical rain forest. Biotropica 19: 149-156.

Gómez-Pompa, A. \& Nevling Jr., L.I. 1988. Some reflections on floristic databases. Taxon 37: 764-775.

Gonçalves, E.G. \& Lorenzi, H. 2007. Morfologia vegetal: organografia e dicionário ilustrado de morfologia das plantas vasculares. $1^{\text {a }}$ ed. Instituto Plantarum de Estudos da Flora, São Paulo. 448p.

Guaratini, M.T.G.; Gomes, E.P.C.; Tamashiro, J.Y. \& Rodrigues, R.R. 2008. Composição florística da Reserva Municipal de Santa Genebra, Campinas, SP. Revista Brasileira de Botânica 31: 323-337.

IBGE. 1991. Manual Técnico da Vegetação Brasileira. Série Manuais Técnicos em Geociências. Número 1. Fundação Instituto Brasileiro de Geografia e Estatística- IBGE, Secretaria do Orçamento e Coordenação da Presidência da República, Rio de Janeiro. 92p.

Ivanauskas, N.M. \& Rodrigues, R.R. 2000. Florística e fitossociologia de remanescentes de floresta estacional decidual em Piracicaba, São Paulo, Brasil. Revista Brasileira de Botânica 23: 291-304.

Köppen, W. 1948. Climatologia. Fondo de Cultura Economica, Mexico City. 478p.

Kotchetkoff-Henriques, O.; Joly, C.A. \& Bernacci, L. 2005. Relação entre o solo e a composição florística de vegetação natural no Município de Ribeirão Preto, SP. Revista Brasileira de Botânica 28: 541-562.

Kronka, F.J.N.; Nalon, M.A. \& Matsukuma, C.K. 2005. Inventário Florestal da Vegetação Natural do Estado de São Paulo. Secretaria do Meio Ambiente, Instituto Florestal, São Paulo. 200p.

Leitão-Filho, H.F. 1987. Considerações sobre a florística de florestas tropicais e sub-tropicais do Brasil. IPEF, 35: 41-46.
Lista de Espécies da Flora do Brasil. 2011 [continuamente atualizada]. Disponível em $<$ http://floradobrasil.jbrj. gov.br/2011/>. Acesso em 1 Dez 2010.

Marcondes-Ferreira, W. 2004. Aspidosperma. In: Wanderley, M.G.L.; Shepherd, G.L.; Melhem, T.S.; Martins, S.E.; Kirizawa, M. \& Giulietti, A.M. (eds.). Flora Fanerogâmica do Estado de São Paulo. Vol 4. FAPESP, RiMa, São Paulo. Pp 39-47.

Mamede, M.C.H.; Souza, V.C.; Prado, J.; Barros, F.; Wanderley, M.G.L. \& Rando, J.G. 2007. Livro vermelho das espécies vegetais ameaçadas do Estado de São Paulo. Instituto de Botânica, Imprensa Oficial, São Paulo. 158p.

Martins, F.R. 1989. Fitossociologia de florestas do Brasil: um histórico bibliográfico. Pesquisas, São Leopoldo 40: 103-164.

Missouri Botanical Garden. 2010 [continuamente atualizado]. Tropicos.org. Disponível em: $<$ http:// www.tropicos.org/>. Acesso em Out 2010.

Mittermeier, R.A.; Gil, P.R.; Hoffmann, M.; Pilgrim, J.; Brooks, J.; Mittermeier, C.G.; Lamourux, J. \& Fonseca, G.A.B. 2004. Hotspots revisited: Earth's biologically richest and most endangered terrestrial ecoregions. CEMEX, Mexico City. 390p.

Myers, N.; Mittermeier, R.A.; Mittermeier, C.G.; Fonseca, G.A.B. \& Kent, J. 2000. Biodiversity hotspots for conservation priorities. Nature 403: 853-858.

Oliveira-Filho, A.T. \& Fontes, M.A. 2000. Patterns of floristic differentiation among Atlantic Forests in Southeastern Brazil and the influence of climate. Biotropica 32: 793-810.

Pinto, L.P. \& Brito, M.C.W. 2005. Dinâmica da perda da biodiversidade na Mata Atlântica: uma introdução. In: Galindo-Leal, C.G. \& Câmara, I.D. (eds.). Mata Atlântica: biodiversidade, ameaças e perspectivas. Fundação SOS Mata Atlântica \& Conservação Internacional. Belo Horizonte. Pp. 27-30.

Porembski, S. 2007. Tropical inselbergs: habitat types, adaptative strategies and diversity patterns. Revista Brasileira de Botânica 30: 579-586.

Prado, D.R. \& Gibbs, P.E. 1993. Patterns of species distributions in the Dry Seasonal Forests of South America. Annals of the Missouri Botanical Garden 80: 902-927.

Queiroz, L.P. 2009. Leguminosas da caatinga. Universidade Estadual de Feira de Santana, Feira de Santana. 467p.

Rapini, A.; Andrade, M.J.G.; Giulietti, A.M.; Queiroz, L.P. \& Silva, J.M.C. 2009. Introdução. In: Giulietti, A. M.; Rapini, A.; Andrade, M. J. G.; Queiroz, L. P. \& Silva, J. M. C. (eds.). Plantas raras do Brasil. Conservação Internacional \& Universidade Estadual de Feira de Santana. Belo Horizonte. Pp. 23-35.

Santos, K.; Kinoshita, L.S. \& Rezende, A.A. 2009. Species composition of climbers in seasonal 
semideciduous forest fragments of Southeastern Brazil. Biota Neotropica 9: 175-188.

São Paulo. 1983. Decreto Estadual no 20.960, de 8 de junho de 1983, que cria a Área de Proteção Ambiental Corumbataí-Botucatu-Tejupá. Imesp, Secretaria do Estado do Meio Ambiente, São Paulo.

Schnitzer, S.A. \& Bongers, F. 2002. The ecology of lianas and their role in forests. Trends in Ecology \& Evolution 17: 223-230.

Smith, A.R.; Pryer, K.M.; Schuettpelz, E.; Korall, P.; Schneider, H. \& Wolf, P.G. 2006. A classification for extant ferns. Taxon 55:705-731.

Sobral, M. \& Stehmann, J.R. 2009. An analysis of new angiosperm species discoveries in Brazil (1990-2006). Taxon 58: 227-232.

Stehmann, J.R.; Forzza, R.C.; Salino, A.; Sobral, M.; Costa, D.P. \& Kamino, L.H.Y. 2009. Floresta Atlântica: riqueza, endemismo e conservação. Diversidade taxonômica na Mata Atlântica. In: Stehmann, J.R.; Forzza, R.C.; Salino, A.; Sobral, M.; Costa, D.P. \& Kamino, L.H.Y (eds.). Plantas da Floresta Atlântica. Jardim Botânico do Rio de Janeiro, Rio de Janeiro. Pp 3-12.

Stranghetti, V. \& Ranga, N.T. 1998. Levantamento florístico das espécies vasculares da floresta estacional mesófila semidecídua da Estação Ecológica de Paulo de Faria - SP. Revista Brasileira de Botânica 21: 289-298.

Thiers, B. 2010. [continuously updated]. Index Herbariorum: a global directory of public herbaria and associated staff. New York Botanical Garden's Virtual Herbarium. Disponível em <http:// sweetgum.nybg.org/ih/>. Acesso em 4 Dez 2010.

Tryon, A.F. 1957. A revision of the ferns genus Pellaea section Pellaea. Annals of the Missouri Botanical Garden 44: 125-193.

Viana, V.M. \& Pinheiro, L.A.F.V. 1998. Conservação da biodiversidade em fragmentos florestais. Série Técnica IPEF - Instituto de Pesquisas e Estudos Florestais 12: 25-42.

Wheeler, Q.D. 2004. Taxonomic triage and the poverty of phylogeny. Philosophical Transactions of the Royal Society of London 359: 571-583.

Wiggins, I.L. 1946. Xerophytic ferns in Ecuador. American Fern Journal 36: 1-7.

Woitke, M. e Dietz, H. 2002. Shifts in dominance of native and invasive plants in experimental patches of vegetations. Perspectives in Plant Ecology, Evolution and Systematics 5: 165-184. 


\title{
Flora vascular da Mata da Pavuna, Botucatu, SP, Brasil
}

\author{
Vascular flora of "Mata da Pavuna", Botucatu, SP, Brazil
}

\section{Leonardo Biral \& Julio Antonio Lombardi}

Apêndice - Lista das espécies vegetais vasculares coletadas na Mata da Pavuna, Botucatu, SP. Habito: Er, ervas; Arb, arbustos; Árv, árvores; T, trepadeiras; Ep, epífitas; Esc, arbustos escandentes; Hem, hemiparasitas. Vouchers: correspondentes ao número de coleta do primeiro autor; números com asterisco (*) coletas de J. Prado. Espécie: \#, cultivadas; $\S$, ruderais; $\varnothing$, ocorrentes nos afloramentos rochosos/floresta estacional decidual. Especialistas que ajudaram em todas ou algumas identificações são citados entre parênteses após o nome da família, assim como a sigla do herbário ao qual estão vinculados.

Appendix - Species list of the vascular plants found in the Mata da Pavuna, municipality of Botucatu, São Paulo State. Habit: Er, herbaceous; Arb, shrubs; Árv, trees; T, climbers; Ep, epiphytes; Esc, scandents, Hem, hemiparasitics. Vouchers: number collection of the first author; numbers with asterisk $(*)$ collected by J. Prado. Species: \#, cultivated; $\S$, weed; $₫$ present in rock outcrops/deciduous forest. Specialists that helped in identifications are listed above families (name between brackets), with their herbarium of association acronym.

\begin{tabular}{|c|c|c|c|}
\hline Família & Espécie & Hábito & Vouchers \\
\hline \multicolumn{4}{|l|}{ Faneróftias } \\
\hline \multirow[t]{4}{*}{ Acanthaceae } & Justicia brasiliana Roth $\varnothing$ & Er & 301 \\
\hline & Justicia lythroides (Ness) V.A.W. Graham & Er & $130,280,527$ \\
\hline & Ruellia brevifolia (Pohl) C. Escurra ф & Er & 227,470 \\
\hline & Thunbergia alata Bojer ex Sims $\S$ & $\mathrm{T}$ & 390 \\
\hline Agavaceae & Herreria salsaparilha Mart. & $\mathrm{T}$ & 586 \\
\hline \multirow[t]{7}{*}{ Amaranthaceae } & Alternanthera brasiliana var. villosa (Moq.) Kuntze & Er & 128,172 \\
\hline & Alternanthera tenella Colla & Er & 266 \\
\hline & Amaranthus hybridus L. § & Er & 397 \\
\hline & Amaranthus spinosus L. $\S$ & Er & 319 \\
\hline & Chamissoa altissima (Jacq.) Kunth & Esc & 272,548 \\
\hline & Gomphrena celosioides Mart. & Er & 388 \\
\hline & Hebanthe paniculata Mart. & Esc & 560 \\
\hline \multirow[t]{3}{*}{ Anacardiaceae } & Mangifera indica $\mathrm{L} . \#$ & Árv & 574 \\
\hline & Schinus terebinthifolius Raddi & Árv & 242 \\
\hline & Spondias purpurea $\mathrm{L} . \#$ & Árv & 145 \\
\hline Annonaceae & Annona sylvatica A. St.-Hil. & Árv & 519 \\
\hline Apiaceae & Ciclospermunm leptophyllum (Pers.) Sprague & Er & 350 \\
\hline \multirow[t]{7}{*}{ Apocynaceae } & Asclepias curassavica L. ф & $\mathrm{Er}$ & 146,247 \\
\hline & Aspidosperma riedelii Müll. Arg. $\varnothing$ & Árv & 195 \\
\hline & Catharanthus roseus (L.) G. Don \# & Er & 244 \\
\hline & Gonolobus sp. $\varnothing$ & $\mathrm{T}$ & 177 \\
\hline & Mandevilla atroviolacea (Stadelm.) Woodson $\varnothing$ & $\mathrm{T}$ & 435 \\
\hline & Rauvolfia sellowii Müll. Arg. & Árv & 384 \\
\hline & Tabernaemontana catharinensis A. DC. & Arb & 149 \\
\hline \multirow{2}{*}{$\begin{array}{l}\text { Araceae (L.G. Temponi - } \\
\text { UNOP) }\end{array}$} & Philodendron appendiculatum Nadruz \& Mayo ф & Esc & 468 \\
\hline & Philodendron bipinnatifidum Schott ex Endl. & Er & 570 \\
\hline
\end{tabular}




\begin{tabular}{|c|c|c|c|}
\hline Família & Espécie & Hábito & Vouchers \\
\hline Araliaceae & Schefflera arboricola (Hayata) Merr. $\S$ & Arb & 490 \\
\hline Arecaceae & Syagrus romanzoffiana (Cham.) Glassman & Árv & 271 \\
\hline Aristolochiaceae & Aristolochia arcuata Mast. & $\mathrm{T}$ & 131 \\
\hline Asteraceae (G. Heiden - & Achyrocline satureidoides (Lam.) DC. & $\mathrm{Er}$ & 112 \\
\hline \multirow[t]{33}{*}{$\begin{array}{l}\text { RB, J. Nakajima - HUFU, } \\
\text { M. Monge - UEC) }\end{array}$} & $\begin{array}{l}\text { Austrocritonia cf. velutina (Gardn.) R.M. King \& } \\
\text { H. Rob. }\end{array}$ & Arb & 359 \\
\hline & Baccharis dracunculifolia DC. & Arb & 255 \\
\hline & Baccharis punctulata DC. & Arb & 139 \\
\hline & Bidens pilosa L. $\S$ & Er & 370 \\
\hline & Blainvillea acmella (L.) Philipson & Er & 369 \\
\hline & Chaptalia integerrima (Vell.) Burkart & $\mathrm{Er}$ & 379 \\
\hline & Conyza bonariensis (L.) Cronquist & Er & 385 \\
\hline & Conyza canadensis (L.) Cronquist & $\mathrm{Er}$ & 477 \\
\hline & Critonia megaphylla (Baker) R.M. King \& H. Rob. & Arb & 296 \\
\hline & Dasyphyllum sp. & Esc & 616 \\
\hline & Elephantopus angustifolia Sw. & $\mathrm{Er}$ & 132 \\
\hline & Elephantopus mollis Kunth $\S$ & $\mathrm{Er}$ & 133 \\
\hline & Emilia fosbergii Nicolson & $\mathrm{Er}$ & 170 \\
\hline & Erechtites hieraciifolius (L.) Raf. ex DC. & $\mathrm{Er}$ & 366 \\
\hline & Eupatorium sp. 1 & Arb & 297,313 \\
\hline & Eupatorium sp. 2 & Arb & 277 \\
\hline & Gochnatia polymorpha (Less.) Cabr. & Árv & 206 \\
\hline & $\begin{array}{l}\text { Heterocondylus aff. vitalbae (DC.) R.M. King \& H. } \\
\text { Rob. }\end{array}$ & Arb & 113,157 \\
\hline & Hieracium sp. & $\mathrm{Er}$ & 367 \\
\hline & Mikania glomerata Spreng. & $\mathrm{T}$ & 339 \\
\hline & Mikania sp. & $\mathrm{T}$ & 111 \\
\hline & Podocoma notobellidiastrum (Griseb.) G.L. Nesom & $\mathrm{Er}$ & 539 \\
\hline & 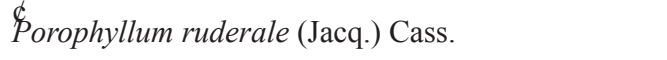 & $\mathrm{Er}$ & 220 \\
\hline & Pterocaulon lanatum Kuntz & $\mathrm{Er}$ & 110 \\
\hline & Pterocaulon virgatum (L.) DC. $\S$ & $\mathrm{Er}$ & 201 \\
\hline & Senecio brasiliensis Less. & Er & 198 \\
\hline & Solidago chilensis Meyen & $\mathrm{Er}$ & 151 \\
\hline & Sonchus oleraceus L. & $\mathrm{Er}$ & 364 \\
\hline & Tridax procumbens L. & Er & 478 \\
\hline & Trixis antimenorrhoea (Schrank) Kuntze & $\mathrm{T}$ & 286,299 \\
\hline & Vernonanthura phosphorica (Vell.) H. Rob. & Arb & $304,305,306$ \\
\hline & Vernonia sp. & Arb & 138 \\
\hline & Indeterminada & Arb & 303 \\
\hline \multirow[t]{3}{*}{ Begoniaceae } & Begonia cucullata Willd. & $\mathrm{Er}$ & 181 \\
\hline & Begonia reniformis Vell. & Arb & 204,225 \\
\hline & Begonia sp. $\varnothing$ & $\operatorname{Er}$ & 221,295 \\
\hline Bignoniaceae (R.G. & Adenocalymma bracteatum (Cham.) DC. & $\mathrm{T}$ & 178 \\
\hline \multirow[t]{2}{*}{ Udulutsch - HRCB) } & Adenocalymma marginatum (Cham.) DC. & $\mathrm{T}$ & $129,234,486$ \\
\hline & Arrabidaea conjugata (Vell.) Mart. $\varnothing$ & $\mathrm{T}$ & 467 \\
\hline
\end{tabular}




\begin{tabular}{|c|c|c|c|}
\hline Família & Espécie & Hábito & Vouchers \\
\hline & Arrabidaea selloi (Spreng.) Sandwith & $\mathrm{T}$ & 447,487 \\
\hline & $\begin{array}{l}\text { Arrabidaea triplinervia (Mart. ex DC.) Baill. ex } \\
\text { Bureau }\end{array}$ & $\mathrm{T}$ & 124 \\
\hline & Clytostoma sciuripabulum Bureau \& K. Schum. & $\mathrm{T}$ & 357 \\
\hline & Fridericia speciosa Mart. & $\mathrm{T}$ & 261 \\
\hline & Lundia obliqua Sond. & $\mathrm{T}$ & 524,583 \\
\hline & Macfadyena unguis-cati (L.) A.H. Gentry & $\mathrm{T}$ & 585 \\
\hline & Pyrostegia venusta Miers $\varnothing$ & $\mathrm{T}$ & 232 \\
\hline & Spathodea campanulata P. Beauv. \# & Árv & 552 \\
\hline & Stizophyllum perforatum (Cham.) Miers & $\mathrm{T}$ & 581 \\
\hline & Tecoma stans (L.) Kunth $\S$ & Árv & 246 \\
\hline \multirow[t]{5}{*}{ Boraginaceae } & Cordia corymbosa Willd. ex Roem. \& Schult. & Arb & 400,483 \\
\hline & Cordia trichotoma (Vell.) Steud. & Árv & 186 \\
\hline & Heliotropium transalpinum Vell. & $\mathrm{Er}$ & 196 \\
\hline & Patagonula americana L. $\varnothing$ & Árv & 557 \\
\hline & Tournefortia paniculata Cham. & $\mathrm{Er}$ & 193 \\
\hline \multirow[t]{4}{*}{ Brassicaceae } & Cardamine bonariensis Pers. $\varnothing$ & $\mathrm{Er}$ & 580 \\
\hline & Lepidium virginicum L. $\S$ & $\mathrm{Er}$ & 432 \\
\hline & Raphanus raphanistrum L. $\S$ & $\mathrm{Er}$ & 154 \\
\hline & Raphanus sativus L. $\S$ & $\mathrm{Er}$ & 258 \\
\hline \multirow{8}{*}{$\begin{array}{l}\text { Bromeliaceae (A.E.M. } \\
\text { Rosa - HRCB) }\end{array}$} & Acanthostachys strobilacea (Schult. f.) Klotzsch & Ep & 450 \\
\hline & Aechmea distichantha Lem. $\varnothing$ & $\mathrm{Er} / \mathrm{Ep}$ & 196 \\
\hline & Tillandsia geminiflora Brongn. & Ep & 420 \\
\hline & Tillandsia loliacea Mart. ex Schult f. $\varnothing$ & Ep & 142 \\
\hline & Tillandsia pohliana $\mathrm{Mez}$ & Ep & 320 \\
\hline & Tillandsia recurvata $\mathrm{L} . \varnothing$ & Ep & 141 \\
\hline & Tillandsia tenuifolia $\mathrm{L}$. & Ep & 449 \\
\hline & Tillandsia tricholepis Baker $\varnothing$ & Ep & 143 \\
\hline \multirow[t]{8}{*}{ Cactaceae } & Cereus hildmannianus K. Schum. $\varnothing$ & Árv & 530 \\
\hline & Epiphyllum phyllanthus (L.) Haw. ф & Ep & 465 \\
\hline & Lepismium cruciforme (Vell.) Miq. & Ep & 590 \\
\hline & Lepismium warmingianum (Schum.) Barthlott & Ep & 452,563 \\
\hline & Praecereus euchlorus (F.A.C. Weber) N.P. Taylor $\varnothing$ & Esc & 464,474 \\
\hline & Rhipsalis cereuscula Haw. & Ep & 329,592 \\
\hline & Rhipsalis floccosa Salm-Dyck ex Preiff. & Ep & 591 \\
\hline & $\begin{array}{l}\text { Rhipsalis paradoxa (Salm-Dyck ex Pfeiff.) Salm- } \\
\text { Dyck } \varnothing\end{array}$ & Ep & 458 \\
\hline \multirow[t]{2}{*}{ Cannabaceae } & Celtis iguanaea (Jacq.) Sarg. ф & Árv & 342 \\
\hline & Trema micrantha (L.) Blume & Árv & 245 \\
\hline Caricaceae & Carica quercifolia (A. St.-Hil.) Hieron. $\varnothing$ & Árv & 188 \\
\hline Caryophyllaceae & Drymaria cordata (L.) Willd. ex Roem. \& Schult. § & $\mathrm{Er}$ & 463 \\
\hline \multirow[t]{3}{*}{ Celastraceae } & Maytenus aquifolia Mart. & Árv & 554 \\
\hline & Hippocratea volubilis L. & $\mathrm{T}$ & 260 \\
\hline & Schaefferia argentinensis Speg. $\varnothing$ & Arb & 589 \\
\hline Commelinaceae & Callisia $\mathrm{sp}$. & $\mathrm{Er}$ & 475 \\
\hline
\end{tabular}




\begin{tabular}{|c|c|c|c|}
\hline Família & Espécie & Hábito & Vouchers \\
\hline \multirow{15}{*}{$\begin{array}{l}\text { Convolvulaceae (R.S. } \\
\text { Bianchini - SP) }\end{array}$} & Commelina benghalensis L. $\varnothing$ & $\mathrm{Er}$ & 197 \\
\hline & Commelina erecta $\mathrm{L}$. & $\mathrm{Er}$ & 179,229 \\
\hline & Commelina cf. obliqua Vahl & Er & 437 \\
\hline & Dichorisandra hexandra (Aubl.) Standl. & Er & 502 \\
\hline & Floscopa glabrata (Kunth) Hassk. & Er & 223 \\
\hline & Gibasis geniculata (Jacq.) Rohweder & $\mathrm{Er}$ & 281 \\
\hline & Tradescantia umbraculifera Hand.-Mazz. & $\mathrm{Er}$ & 528 \\
\hline & Tradescantia zanonia (L.) Sw. & Er & 222 \\
\hline & Ipomoea bonariensis Hook. $\varnothing$ & $\mathrm{T}$ & 482,504 \\
\hline & Ipomoea cairica (L.) Sw. & $\mathrm{T}$ & 387 \\
\hline & Ipomoea megapotamica Choisy $\varnothing$ & $\mathrm{T}$ & 526 \\
\hline & Ipomoea nil (L.) Roth. & $\mathrm{T}$ & 386 \\
\hline & Ipomoea purpurea (L.) Roth. & $\mathrm{T}$ & 381 \\
\hline & Ipomoea quamoclit L. & $\mathrm{T}$ & 290 \\
\hline & Ipomoea triloba $\mathrm{L} . \S$ & $\mathrm{T}$ & 180 \\
\hline \multirow[t]{2}{*}{ Cucurbitaceae } & Momordica charantia L. ф & $\mathrm{T}$ & 203 \\
\hline & Wilbrandia longibracteata Cogn. & $\mathrm{T}$ & 413,495 \\
\hline \multirow{8}{*}{$\begin{array}{l}\text { Cyperaceae (M.V. Alves } \\
\text { - UFP) }\end{array}$} & Cyperus cf. laxus Lam. & $\mathrm{Er}$ & 166 \\
\hline & Cyperus luzulae (L.) Rottb. ex Retz & $\mathrm{Er}$ & 443 \\
\hline & Cyperus meyenianus Kunth $\S$ & Er & 168 \\
\hline & Cyperus sp. 1 & $\mathrm{Er}$ & 215 \\
\hline & Cyperus sp. 2 & $\mathrm{Er}$ & 503 \\
\hline & Eleocharis sellowiana Kunth & $\mathrm{Er}$ & 202 \\
\hline & Fimbristylis dichotoma (L.) Vahl & $\mathrm{Er}$ & 118 \\
\hline & Scleria melaleuca Rhcb. ex Schltdl. \& Cham. & $\mathrm{Er}$ & 187 \\
\hline Dioscoriaceae & Dioscorea multiflora Griseb. & $\mathrm{T}$ & 268,588 \\
\hline Ebenaceae & Diospyros inconstans Jacq. $\varnothing$ & Árv & 241 \\
\hline \multirow[t]{16}{*}{ Euphorbiaceae } & Acalypha gracilis Spreng. & $\mathrm{Er}$ & 245,279 \\
\hline & Acalypha sp. ф & $\mathrm{Er}$ & 308 \\
\hline & Actinostemon concolor (Spreng.) Müll. Arg. $\varnothing$ & Arb & 338 \\
\hline & $\begin{array}{l}\text { Actinostemon concepcionis (Chodat \& Hassl.) } \\
\text { Hochr. }\end{array}$ & Arb & 347,428 \\
\hline & Croton gracilipes Baill. ф & Arb & $278,307,399$ \\
\hline & Croton lundianus Müll. Arg. & $\mathrm{Er}$ & 371 \\
\hline & Dalechampia stipulacea Müll. Arg. & $\mathrm{T}$ & 356 \\
\hline & Euphorbia heterophylla L. & $\mathrm{Er}$ & 108 \\
\hline & Euphorbia hirta L. & Er & 243 \\
\hline & Euphorbia hyssopifolia L. & $\mathrm{Er}$ & 136 \\
\hline & Euphorbia prostrata Aiton & $\mathrm{Er}$ & 431 \\
\hline & Euphorbia pulcherrima Willd. ex Klotzsch \# & Arb & 561 \\
\hline & Euphorbia sp. ф & $\mathrm{Er}$ & 289 \\
\hline & Manihot sp. $\varnothing$ & Arb & 424 \\
\hline & Ricinus communis L. & Arb & 137 \\
\hline & Tragia sellowiana Müll. Arg. & $\mathrm{T}$ & 439 \\
\hline
\end{tabular}




\begin{tabular}{|c|c|c|c|}
\hline Família & Espécie & Hábito & Vouchers \\
\hline & Indeterminada 1 & Arb & 401 \\
\hline & Indeterminada 2 & $\mathrm{Er}$ & 322,489 \\
\hline \multirow{11}{*}{$\begin{array}{l}\text { Fabaceae } \\
\text { (Caesalpinoideae) }\end{array}$} & Caesalpinia pulcherrima (L.) Sw. \# & Árv & 480 \\
\hline & Chamaecrista nictitans (L.) Moench & $\mathrm{Er}$ & 514 \\
\hline & Holocalyx balansae Micheli & Árv & 553 \\
\hline & Hymenaea courbaril L. & Árv & 569 \\
\hline & Peltophorum dubium (Spreng.) Taub. $\varnothing$ & Árv & 240 \\
\hline & Schizolobium parahyba (Vell.) S.F. Blake & Árv & 264 \\
\hline & Senna bicapsularis (L.) Roxb. & Arb & 551 \\
\hline & Senna hirsuta (L.) H.S. Irwin \& Barneby & $\mathrm{Er}$ & 134 \\
\hline & Senna multijuga (Rich.) H.S. Irwin \& Barneby & Árv & 529 \\
\hline & Senna obtusifolia (L.) H.S. Irwin \& Barneby & $\mathrm{Er}$ & 152 \\
\hline & Senna pendula (Willd.) H.S. Irwin \& Barneby & Árv & 121 \\
\hline \multirow[t]{2}{*}{ (Cercideae) } & Bauhinia forficata Link & Árv & 122 \\
\hline & Bauhinia variegata L. \# & Árv & 273 \\
\hline \multirow[t]{23}{*}{ (Faboideae) } & Aeschynomene paniculata Willd. ex Vogel & $\operatorname{Er}$ & 183 \\
\hline & Cajanus cajan (L.) Huth $\S$ & Arb & 577 \\
\hline & Camptosema grandiflorum Benth. & $\mathrm{T}$ & 199,564 \\
\hline & Centrolobium tomentosum Guill. ex Benth. & Árv & 516 \\
\hline & $\begin{array}{l}\text { Centrosema sagittatum (Humb. \& Bonpl. ex Willd.) } \\
\text { Brandegee }\end{array}$ & $\mathrm{T}$ & 282 \\
\hline & Crotalaria lanceolata E. Mey. $\S$ & $\mathrm{Er}$ & 194,253 \\
\hline & Crotalaria pallida Aiton $\S$ & Er & 120 \\
\hline & Crotalaria stipularia Desv. & $\mathrm{Er}$ & 454 \\
\hline & Dalbergia frutescens (Vell.) Britton & Árv & 389 \\
\hline & Desmodium adscendens (Sw.) DC. & $\mathrm{Er}$ & 522 \\
\hline & Desmodium affine Schltdl. & $\mathrm{Er}$ & 440 \\
\hline & Desmodium incanum DC. & $\mathrm{Er}$ & 355 \\
\hline & Desmodium uncinatum (Jacq.) DC. & $\mathrm{Er}$ & 461 \\
\hline & Indigofera suffruticosa Mill. & $\mathrm{Er}$ & 126 \\
\hline & Lonchocarpus guilleminianus (Tul.) Malme & Árv & 167,427 \\
\hline & Machaerium nyctitans (Vell.) Benth. & Árv & 163 \\
\hline & Machaerium scleroxylon Tul. ф & Árv & 312 \\
\hline & $\begin{array}{l}\text { Macroptilium atropurpureum (Moc. \& Sessé ex } \\
\text { DC.) Urb. § }\end{array}$ & $\mathrm{T}$ & 153 \\
\hline & Stylosanthes guianensis (Aubl.) Sw. & $\mathrm{Er}$ & 191 \\
\hline & Stylosanthes scabra Vogel & $\mathrm{Er}$ & 192 \\
\hline & Vigna sp. 1. & $\mathrm{~T}$ & 438 \\
\hline & Vigna sp. 2. & $\mathrm{~T}$ & 540 \\
\hline & Zornia gemella Vogel & Er & 368,518 \\
\hline \multirow[t]{5}{*}{ (Mimosoideae) } & Calliandra foliosa Benth. $\varnothing$ & Arb & 341 \\
\hline & Calliandra inaequilatera Rusby \# & Arb & 555 \\
\hline & Inga marginata Willd. & Árv & 417,498 \\
\hline & Mimosa bimucronata (DC.) Kuntze $\varnothing$ & Árv & $158,520,536$ \\
\hline & Parapiptadenia rigida (Benth.) Brenan $\varnothing$ & Árv & 559 \\
\hline
\end{tabular}




\begin{tabular}{|c|c|c|c|}
\hline Família & Espécie & Hábito & Vouchers \\
\hline \multirow{6}{*}{ Gesneriaceae } & Piptadenia gonoacantha (Mart.) J.F. Macbr. & Árv & 174 \\
\hline & Senegalia tenuifolia (L.) Britton \& Rose $\varnothing$ & Esc & 515 \\
\hline & Indeterminada & Árv & 117 \\
\hline & Sinningia aggregata (Ker Gawl.) Wiehler $\varnothing$ & Er & 354 \\
\hline & Sinningia eumorpha H.E. Moore & Er & 484 \\
\hline & Sinningia piresiana (Hoehne) Chautems $\varnothing$ & Er & 353 \\
\hline Hypoxidaceae & Hypoxis decumbens L. & $\mathrm{Er}$ & 200 \\
\hline \multirow[t]{6}{*}{ Lamiaceae } & Aegiphila sellowiana Cham. & Árv & 549 \\
\hline & Hyptis suaveolens (L.) Poit. & Arb & 460 \\
\hline & Leonotis nepetifolia (L.) R. Br. § & $\mathrm{Er}$ & 257 \\
\hline & Leonorus japonicus Houtt. $\S$ & $\mathrm{Er}$ & 107 \\
\hline & Ocimum campechianum Mill. & Er & 462 \\
\hline & Ocimum selloi Benth. & $\mathrm{Er}$ & 230 \\
\hline \multirow{2}{*}{$\begin{array}{l}\text { Lauraceae (F.M. Alves } \\
- \text { SPF) }\end{array}$} & Nectandra megapotamica (Spreng.) Mez & Árv & 332,425 \\
\hline & Persea americana Mill. \# & Árv & 348 \\
\hline \multirow[t]{2}{*}{ Loganiaceae } & Spigelia scabra Cham. \& Schultdl. & Er & 411 \\
\hline & Strychnos brasiliensis (Spreng.) Mart. $\varnothing$ & Esc & 510 \\
\hline Loranthaceae & Struthanthus vulgaris Mart. & Hem & 159 \\
\hline Lythraceae & $\begin{array}{l}\text { Cuphea calophylla Cham. \& Schltdl. subsp. } \\
\text { mesostemon (Koehne) Lourteig }\end{array}$ & Er & 383 \\
\hline \multirow{9}{*}{$\begin{array}{l}\text { Malpighiaceae (M.C.H. } \\
\text { Mamede - SP) }\end{array}$} & Banisteriopsis muricata (Cav.) Cuatrec. $\varnothing$ & $\mathrm{T}$ & 509,550 \\
\hline & Dicella bracteosa (A. Juss.) Griseb. & $\mathrm{T}$ & 545 \\
\hline & Heteropteris cochleosperma A. Juss. & $\mathrm{T}$ & 119,250 \\
\hline & Heteropterys dumetorum (Griseb.) Nied. $\varnothing$ & $\mathrm{T}$ & 571 \\
\hline & Heteropteris sp. & $\mathrm{T}$ & 429,584 \\
\hline & Janusia guaranitica (A. St.-Hil.) A. Juss. & $\mathrm{T}$ & 162 \\
\hline & Malpighia glabra L. \# & Arb & 507 \\
\hline & Niedenzuella acutifolia (Cav.) W.R. Anderson & $\mathrm{T}$ & 164 \\
\hline & Indeterminada & $\mathrm{T}$ & 471 \\
\hline \multirow{16}{*}{$\begin{array}{l}\text { Malvaceae (A. } \\
\text { Krapovickas - CTES, } \\
\text { G.L. Esteves - SP) }\end{array}$} & Abelmoschus esculentus(L.) Moench $\S$ & Arb & 256 \\
\hline & Byttneria australis A. St.-Hil. ф & Esc & 453 \\
\hline & Ceiba speciosa (A. St.-Hil.) Ravenna ф & Árv & 538 \\
\hline & Gaya dominguensis Urb. & Er & 292 \\
\hline & Guazuma ulmifolia Lam. & Árv & 336 \\
\hline & Hibiscus rosa-sinensis L. \# & Árv & 274 \\
\hline & Luehea divaricata Mart. $\varnothing$ & Árv & 525 \\
\hline & Pavonia communis A. St.-Hil. & Arb & 171,274 \\
\hline & Pavonia sepium A. St.-Hil. & Arb & 135,457 \\
\hline & Sida rhombifolia $\mathrm{L}$. & $\operatorname{Er}$ & 372 \\
\hline & Sida urens L. & Er & 542 \\
\hline & Triumfetta rhomboidea Jacq. & Arb & 205 \\
\hline & Triumfetta semitriloba Jacq. & Arb & 485 \\
\hline & Waltheria americana $\mathrm{L}$. & $\operatorname{Er}$ & 115 \\
\hline & Wissadula hernandioides (L' Hér.) Garcke & Er & 125 \\
\hline & Wissadula cf. subpeltata (Kuntze) R.E. Fr. & $\mathrm{Er}$ & 216 \\
\hline
\end{tabular}




\begin{tabular}{|c|c|c|c|}
\hline Família & Espécie & Hábito & Vouchers \\
\hline Marantaceae & Calathea sp. & Er & 469 \\
\hline Melastomataceae (R. & Miconia collatata Wurdack & Árv & 343,404 \\
\hline \multirow[t]{2}{*}{ Goldenberg - UPCB) } & Rhynchanthera sp. & $\mathrm{Er}$ & 182 \\
\hline & Tibouchina cerastifolia Cogn. & Er & 556 \\
\hline \multirow[t]{6}{*}{ Meliaceae } & Cedrela fissilis Vell. & Árv & 593 \\
\hline & Guarea kunthiana A. Juss. & Árv & 335 \\
\hline & Guarea macrophylla Vahl & Árv & 418,451 \\
\hline & Trichilia catigua A. Juss. & Árv & 224,408 \\
\hline & Trichilia claussenii C. DC. & Árv & 349 \\
\hline & Trichilia elegans A. Juss. & Árv & 210 \\
\hline Menispermaceae & Odontocarya acuparata Miers & $\mathrm{T}$ & 506 \\
\hline Monimiaceae & Mollinedia widgrenii A. DC. & Árv & 568 \\
\hline \multirow[t]{5}{*}{ Moraceae } & Artocarpus heterophyllus Lam. \# & Árv & 323 \\
\hline & Ficus guaranitica Chodat $\varnothing$ & Árv & 302 \\
\hline & Ficus insipida Willd. & Árv & 430 \\
\hline & Morus nigra L. \# & Árv & 575 \\
\hline & $\begin{array}{l}\text { Sorocea bonplandii (Baill.) W.C. Burger, Lanj. \& } \\
\text { Bôer }\end{array}$ & Árv & 363 \\
\hline Myrsinaceae & Ardisia ambigua Mart. $\varnothing$ & Árv & 532 \\
\hline \multirow[t]{9}{*}{ Myrtaceae } & Calyptranthes concinna DC. & Árv & 394 \\
\hline & Eucalyptus citriodora Hook. \# & Árv & 219 \\
\hline & Eucalyptus sp. \# & Árv & 173 \\
\hline & Eugenia hyemalis Cambess. & Arb & 558 \\
\hline & Eugenia pyriformis Cambess. & Arb & 365 \\
\hline & Eugenia uniflora $\mathrm{L}$. & Árv & 403 \\
\hline & Eugenia sp. & Árv & 406,491 \\
\hline & Psidium guajava L. $\S$ & Árv & 218 \\
\hline & Syzygium cumini (L.) Skeels \# & Árv & 576 \\
\hline \multirow[t]{3}{*}{ Onagraceae } & Ludwigia leptocarpa (Nutt.) H. Hara & Er & 254 \\
\hline & Ludwigia longifolia (DC.) H. Hara & Er & 488 \\
\hline & Ludwigia sp. & Arb & 265 \\
\hline \multirow{8}{*}{$\begin{array}{l}\text { Orchidaceae (F. Barros } \\
- \text { SP) }\end{array}$} & Anathallis obovata (Lindl.) Pridgeon \& M.W. Chase & Ep & 573 \\
\hline & Cattleya loddigesii Lindl. & Ep & 327 \\
\hline & Cyclopogon congestus (Vell.) Hoehne & Er & 334 \\
\hline & Cyclopogon sp. & Er & 328 \\
\hline & Isochilus linearis (Jacq.) Br. ф & Ep & 562 \\
\hline & Oeceoclades maculata (Lindl.) Lindl. & Er & $284,300,321$ \\
\hline & Polystachya estrellensis Rchb. f. & Ep & 505 \\
\hline & Specklinia leptotifolia (Barb. Rodr.) F. Barros $\varnothing$ & Ep & 572 \\
\hline \multirow[t]{2}{*}{ Oxaliadaceae } & Oxalis rhombeo-ovata A. St.-Hil. & Er & 228 \\
\hline & Oxalis triangularis A. St.-Hil. $\varnothing$ & $\mathrm{Er}$ & 331 \\
\hline \multirow[t]{3}{*}{ Passifloraceae } & Passiflora alata Curtis & $\mathrm{T}$ & 517 \\
\hline & Passiflora suberosa L. ф & $\mathrm{T}$ & 380 \\
\hline & Passiflora tenuifila Killip & $\mathrm{T}$ & 423 \\
\hline Phyllantaceae & Phyllanthus tenellus Roxb. $\varnothing$ & $\mathrm{Er}$ & 267 \\
\hline
\end{tabular}




\begin{tabular}{|c|c|c|c|}
\hline Família & Espécie & Hábito & Vouchers \\
\hline Phytolaccaceae & Gallesia integrifolia (Spreng.) Harms & Árv & 566 \\
\hline \multirow[t]{7}{*}{ Piperaceae } & Peperomia blanda Kunth & Er & 237,276 \\
\hline & Peperomia nitida Dahlst. & $\mathrm{Er}$ & 226,314 \\
\hline & Peperomia circinnata Link & Ep & 409 \\
\hline & Piper aduncum L. & Arb & $213,392,446$ \\
\hline & Piper amalago L. & Arb & 398 \\
\hline & Piper umbellatum $\mathrm{L}$. & Arb & 217 \\
\hline & Piper sp. & Arb & 445 \\
\hline Plantaginaceae & Plantago tomentosa Lam. & Er & 414 \\
\hline \multirow{18}{*}{$\begin{array}{l}\text { Poaceae (J.F.M. Valls - } \\
\text { CEN) }\end{array}$} & Andropogon bicornis L. $\varnothing$ & $\mathrm{Er}$ & 109 \\
\hline & Aristida jubata (Arechav.) Herter & $\mathrm{Er}$ & 374 \\
\hline & Chloris elata Desv. & Er & 393 \\
\hline & Digitaria insularis (L.) Fedde $\S$ & $\mathrm{Er}$ & 155 \\
\hline & Hyparrhenia rufa (Ness) Stapf $\S$ & $\mathrm{Er}$ & 262 \\
\hline & Lasiacis divaricata (L.) Hitch. & $\mathrm{Er}$ & 293 \\
\hline & $\begin{array}{l}\text { Megathyrsus maximus (Jacq.) B.K. Simon \& S.W.L. } \\
\text { Jacobs } \$\end{array}$ & $\mathrm{Er}$ & 375 \\
\hline & Melinis minutiflora P. Beauv. $\S$ & $\mathrm{Er}$ & 378 \\
\hline & Melinis repens (Willd.) Zizka $\S$ & $\mathrm{Er}$ & 373 \\
\hline & Olyra ciliatifolia Raddi & $\mathrm{Er}$ & 531 \\
\hline & Oplismenus hirtellus (L.) P. Beauv. & $\mathrm{Er}$ & 291 \\
\hline & Paspalum paniculatum $\mathrm{L}$. & $\mathrm{Er}$ & 156 \\
\hline & Pennisetum purpureum Schum. $\S$ & Er & 283 \\
\hline & Pharus lappulaceus Aubl. & $\mathrm{Er}$ & 288 \\
\hline & Pseudechinolaena polystachya (Kunth) Stapf & Er & 456 \\
\hline & Setaria vulpiseta (Lam.) Roem. \& Schult. & $\mathrm{Er}$ & 521,533 \\
\hline & Urochloa brizantha (Hochst. ex A. Rich.) & $\mathrm{Er}$ & 541 \\
\hline & R.D. Webster $\S, \varnothing$ & & \\
\hline Polygalaceae (J.F.B. & Polygala acuminata Willd. & $\mathrm{Er}$ & 441,459 \\
\hline Pastore - HUEFS) & Polygala violacea Aubl. & $\mathrm{Er}$ & 442 \\
\hline Portulacaceae & Talinum paniculatum (Jacq.) Gaertn. & $\mathrm{Er}$ & 333 \\
\hline Rhamnaceae & Gouania virgata Reiss. & $\mathrm{T}$ & 114,358 \\
\hline \multirow[t]{7}{*}{ Rubiaceae } & Coffea arabica L. ${ }^{\#}$ & $\operatorname{Er}$ & 248,434 \\
\hline & Guettarda uruguensis Cham. \& Schltdl. $\varnothing$ & Arb & 512 \\
\hline & Ixora venulosa Benth. & Árv & 405,565 \\
\hline & Psychotria carthagenensis Jacq. & Arb & 410,499 \\
\hline & Randia armata (Sw.) DC. $\varnothing$ & Árv & 337 \\
\hline & Richardia brasiliensis Gomes & $\operatorname{Er}$ & 252 \\
\hline & Rudgea jasminoides (Cham.) Müll. Arg. ф & Árv & 500 \\
\hline \multirow[t]{6}{*}{ Rutaceae } & Citrus limonia Osbeck $\S$ & Árv & 351 \\
\hline & $\begin{array}{l}\text { Conchocarpus pentandrus (A. St.-Hil.) Kallunki \& } \\
\text { Pirani }\end{array}$ & Arb & 317,352 \\
\hline & Helietta apiculata Benth. $\varnothing$ & Árv & 476 \\
\hline & Metrodorea nigra A. St.-Hil. & Árv & 407 \\
\hline & Pilocarpus pauciflorus A. St.-Hil. & Árv & 508 \\
\hline & Zanthoxylum caribaeum Lam. & Árv & 318 \\
\hline
\end{tabular}




\begin{tabular}{|c|c|c|c|}
\hline Família & Espécie & Hábito & Vouchers \\
\hline & Zanthoxylum rhoifolium Lam. & Árv & 546 \\
\hline Salicaceae & Casearia sylvestris Sw. & Árv & 361,396 \\
\hline \multirow{2}{*}{$\begin{array}{l}\text { Santalaceae (J. Rigon - } \\
\text { UPCB) }\end{array}$} & Phoradendron bathyoryctum Eichler & Hem & 190 \\
\hline & Phoradendron piperoides (Kunth) Trel. & Hem & 492 \\
\hline \multirow[t]{7}{*}{$\begin{array}{l}\text { Sapindaceae (M.S. } \\
\text { Ferruci - CTES) }\end{array}$} & $\begin{array}{l}\text { Allophylus edulis (A. St.-Hil., Cambess. \& A. Juss.) } \\
\text { Radlk. }\end{array}$ & Árv & 395 \\
\hline & Paullinia meliifolia Juss. & $\mathrm{T}$ & $214,402,494$, \\
\hline & Serjania caracasana (Jacq.) Willd. & $\mathrm{T}$ & $\begin{array}{l}501 \\
582\end{array}$ \\
\hline & Serjania meridionalis Cambess. & $\mathrm{T}$ & 140,416 \\
\hline & Serjania pinnatifolia Radlk. & $\mathrm{T}$ & $116,185,523$ \\
\hline & Serjania sp. 1. & $\mathrm{~T}$ & 537 \\
\hline & Urvillea laevis Radlk. & $\mathrm{T}$ & 233 \\
\hline \multirow[t]{2}{*}{ Sapotaceae } & Chrysophyllum gonacarpum (Mart. \& Eichler) Engl. & Árv & 239 \\
\hline & Chrysophyllum marginatum (Hook. \& Arn) Radlk. & Árv & 360,481 \\
\hline Scrophulariaceae & Buddleja stachyoides Cham. \& Schltdl. & Er & 311 \\
\hline Smilacaceae & Smilax elastica Griseb. & $\mathrm{T}$ & 578 \\
\hline \multirow[t]{13}{*}{$\begin{array}{l}\text { Solanaceae (L. Giacomin } \\
-\mathrm{BHCB})\end{array}$} & $\begin{array}{l}\text { Brugmansia suaveolens (Humb. \& Bonpl. ex Willd.) } \\
\text { Bercht. \& J. Presl § }\end{array}$ & Arb & 298 \\
\hline & Brunfelsia uniflora (Pohl) D. Don \# & Arb & 547 \\
\hline & Capsicum baccatum $\mathrm{L}$. & $\mathrm{Er}$ & 160 \\
\hline & Cestrum strigilatum Ruiz \& Pav. & Arb & 175,579 \\
\hline & Solanum americanum Mill. & $\mathrm{Er}$ & 249 \\
\hline & Solanum argenteum Dunal & Arb & 285 \\
\hline & Solanum campaniforme Roem. \& Schult. & Árv & 534 \\
\hline & Solanum granulosoleprosum Dunal $\varnothing$ & Arb & 144 \\
\hline & Solanum palinacanthum Dunal & $\mathrm{Er}$ & 184,382 \\
\hline & Solanum paniculatum L. $\notin$ & Arb & 150,426 \\
\hline & Solanum pseudocapsicum L. & Er & 436 \\
\hline & Solanum sisymbriifolium Lam. & $\mathrm{Er}$ & 391 \\
\hline & Solanum viarum Dunal & $\mathrm{Er}$ & 315 \\
\hline Trigoniaceae & Trigonia nivea Cambess. & $\mathrm{T}$ & 269,270 \\
\hline Typhaceae & Typha latifolia $\mathrm{L}$. & $\mathrm{Er}$ & 376 \\
\hline \multirow{6}{*}{$\begin{array}{l}\text { Urticaceae (A. Gaglioti } \\
- \text { SP) }\end{array}$} & Boehmeria ulmifolia Wedd. & Árv & 567 \\
\hline & Cecropia pachystachya Trécul & Árv & 259 \\
\hline & Pilea microphylla Liebm. & Er & 309 \\
\hline & Pilea pubescens Liebm. & Er & 535 \\
\hline & Urera baccifera (L.) Gaudich. & Arb & 251 \\
\hline & Urera caracasana (Jacq.) Griseb. $\varnothing$ & $\mathrm{Arb} / \mathrm{Esc}$ & 466 \\
\hline \multirow[t]{6}{*}{ Verbenaceae } & Aloysia virgata (Ruiz \& Pav.) Pers. $\varnothing$ & Arb & 587 \\
\hline & Duranta repens L. var. aurea Hort. \# & Arb & 275 \\
\hline & Lantana canescens Kunth & Arb & 161,326 \\
\hline & Lantana fucata Lindl. & $\mathrm{Er}$ & 346 \\
\hline & Lantana trifolia $\mathrm{L}$. & Arb & 127 \\
\hline & Petrea subserrata Cham. & $\mathrm{T}$ & 340 \\
\hline
\end{tabular}




\begin{tabular}{|c|c|c|c|}
\hline Família & Espécie & Hábito & Vouchers \\
\hline & Stachytarpheta cayennensis (Rich.) Vahl & Er & 148 \\
\hline & Verbena litoralis Kunth & $\mathrm{Er}$ & 545 \\
\hline Violaceae & Hybanthus bigibbosus (A. St.-Hil.) Hassl. & Arb & 344,419 \\
\hline \multirow[t]{3}{*}{ Vitaceae } & Cissus serroniana (Glaz.) Lombardi & $\mathrm{T}$ & 472 \\
\hline & Cissus simsiana Schult. \& Schult. f. & $\mathrm{T}$ & 209 \\
\hline & $\begin{array}{l}\text { Cissus verticillata (L.) Nicolson \& C.E. Jarvis } \\
\text { subsp. verticillata }\end{array}$ & $\mathrm{T}$ & 493 \\
\hline Zingiberaceae & Hedychium coronarium J. König $\S$ & $\mathrm{Er}$ & 147,165 \\
\hline \multicolumn{4}{|l|}{ Pteridófitas } \\
\hline $\begin{array}{l}\text { Anemiaceae (J. Prado } \\
-\mathrm{SP})\end{array}$ & Anemia phyllitidis (L.) Sw. & Er & 207,236 \\
\hline \multirow{4}{*}{$\begin{array}{l}\text { Aspleniaceae (A. Salino - } \\
\text { BHCB, J. Prado - SP) }\end{array}$} & Asplenium cf. abscissum Willd. & $\mathrm{Er}$ & 330 \\
\hline & Asplenium formosum Willd. & $\mathrm{Er}$ & 316 \\
\hline & Asplenium otites Link & $\mathrm{Er}$ & $2152 *$ \\
\hline & Asplenium pumilum $\mathrm{Sw}$. & $\mathrm{Er}$ & $2151^{*}$ \\
\hline Blechnaceae & Blechnum brasiliense Desv. & $\mathrm{Er}$ & 362 \\
\hline Lomariopsidaceae & Nephrolepis sp. & Er & 544 \\
\hline \multirow{7}{*}{$\begin{array}{l}\text { Polypodiaceae (A. Salino } \\
\text { - BHCB, J. Prado - SP) }\end{array}$} & Campyloneurum rigidum J. Sm. & Ep & 448 \\
\hline & Microgramma lindbergii (Mett. ex Kuhn) de la Sota & Ep & 444 \\
\hline & Microgramma squamulosa (Kaulf.) de la Sota & Ep & 231 \\
\hline & Pecluma filicula (Kaulf.) M.G. Prince & Ep & 496 \\
\hline & Pleopeltis pleopeltifolia (Raddi) Alston & Ep & 455 \\
\hline & Pleopeltis squalida (Vell.) de la Sota & Ep & 294,497 \\
\hline & Serpocaulon catharinae (Langsd. \& Fisch.) A.R. Sm. & Ep & 412 \\
\hline \multirow{9}{*}{$\begin{array}{l}\text { Pteridaceae (A. Salino - } \\
\text { BHCB, J. Prado - SP) }\end{array}$} & Adiantopsis chlorophylla (Sm.) Fée & $\mathrm{Er}$ & 189 \\
\hline & Adiantum lorentzii Hieron. & $\mathrm{Er}$ & 310 \\
\hline & Doryopteris concolor (Langsd. \& Fisch.) Kuhn & Er & 238 \\
\hline & Heminiotis tomentosa (Lam.) Raddi $\varnothing$ & $\mathrm{Er}$ & 208,235 \\
\hline & Pellaea ovata (Desv.) Weath. $\varnothing$ & $\mathrm{Er}$ & 511 \\
\hline & Pityrogramma calomelanos (L.) Link & Er & 287,377 \\
\hline & Pityrogramma trifoliata (L.) R.M. Tryon & Er & 324 \\
\hline & Pteris denticulata $\mathrm{Sw}$. & Er & $2153^{*}$ \\
\hline & Pteris vittata $\mathrm{L}$. & $\mathrm{Er}$ & 123 \\
\hline Thelypteridaceae (A. & Macrothelypteris torresiana (Gaudi.) Ching $\S$ & $\mathrm{Er}$ & 212 \\
\hline Salino - BHCB, J. Prado & Thelypteris conspersa (Forssk.) E.P. St. John & $\mathrm{Er}$ & 263 \\
\hline$-\mathrm{SP})$ & Thelypteris dentata (Forssk.) E.P. St. John $\S$ & $\mathrm{Er}$ & $211,325,433$ \\
\hline $\begin{array}{l}\text { Woodsiaceae } \\
\text { (A. Salino - BHCB) } \\
\text { Licófitas }\end{array}$ & Deparia petersenii (Kuntze) M. Kato & Er & 415 \\
\hline $\begin{array}{l}\text { Selaginallaceae } \\
\text { (J. Prado - SP) }\end{array}$ & Selaginella microphylla (Kunth) Spring & Er & $2144^{*}$ \\
\hline
\end{tabular}

